\title{
LA LENGUA POÉTICA SEGÚN JAN MUKAROVSKY
}

Jan Mukarovsky es considerado el padre de la estética estructural. Fue uno de los más destacados miembros del Círculo Lingüístico de Praga y colaboró en la elaboración de las Tesis de 1929. Sin embargo su estructuralismo está ligado no sólo a la lingüística sino a los llamados "factores extraliterarios", o semiológicos, que de alguna manera significativa se relacionan con la obra de arte. De las conexiones entre lin. güística y poética, propias del formalismo ruso en su etapa inicial, se pasó a una relación más estrecha entre poética y semiología gracias a Mukarovsky. El maestro checó amplió los marcos conceptuales del formalismo ruso hasta llegar a la conclusión de que "la poética formaba parte integral de la semiótica, más que ser una rama de la lingüística", al decir de Victor Erlich. ${ }^{1}$

Mukarovsky murió en 1975. Había nacido en 1891. Enseñó en las universidades de Bratislava y Praga. Es autor de una teoría social de la estética, contenida en Capitulos de poesia checa, La función, la norma y el valor estético como hechos sociales y Estructura, signo y función, una colección de veintiocho artículos traducidos del checo por los profesores norteamericanos John Burbank y Peter Steiner. El ensayo de Mukarovsky sobre la "lengua poética" pertenece a citada colección y fue ofrecido al público por la Universidad de Yale en 1976, como un anticipo de al edición completa de la antes mencionada antología de ensayos. A continuación comentaremos algunas de las ideas principales sobre al lengua poética, muchas de las cuales tienen el valor de postulados estéticos.

1. Ante todo, la lengua poética no es expresión ornamental. Esta primera característica no está precisada en lo que al concepto de 'ornato' se refiere. Para los antiguos retóricos el ornatus estaba constituido, tanto por las figuras de dic-

I Victor Erlich, El formalismo ruso, Seix Barral, Barcelona, 1974; p. 227. 
ción que "afectan al embellecimiento de la disposición elocutiva", como por las figuras de pensamiento que "se refieren al embellecimiento de los medios expresivos conceptuales más allá de la concretización elocutiva". Ambas eran eesnciales al discurso bello, para la retórica tradicional.

Mukarovsky advierte que se han dado periodos en la historia del desarrollo del arte en que expresión lingǘstica y contenido o fondo se separan, considerando a la primera como ropaje o vestidura del segundo. También en épocas clásicas se nota una compenetración íntima de estos dos elementos. Con todo, "no es la belleza la señal constante de la palabra poética", pues, en muchas ocasiones, los poetas no seleccionan su vocabulario con criterio estetizante sino que, por el contrario, extraen sus materiales léxicos de usos cotidianos y sencillos, opuestos a las modelos de belleza imperantes. Jan Neruda y César Vallejo son ejemplos clásicos de que lo ornamentalmente bello no es característico de la lengua poética.

1.2. Esta predilección por la palabra, sensorialmente bella, se relaciona --como es natural- con la selección del vocabulario para la elaboración de una determinada obra. El poeta tiene siempre en el momento de crear, ya sea consciente o inconscientemente, una intención semántica y una intencionalidad estética que rigen, por igual, en el momento de elegir las palabras. Los poeticismos, según Mukarovsky, son los "instrumentos léxicos propios del lenguaje poético"; pero, "éstos comprenden apenas una de las esferas léxicas de entre las cuales el poeta selecciona", lo que significa que también hay otras esferas. "El mismo término de "poeticismo' no deja de ser ambiguo: en algunas ocasiones designa el conjunto de palabras que la tradición considera como 'poéticas'; en otras, el conjunto de palabras que caracterizan distintamente el vocabulario de un poeta o de una escuela determinada." 3

2. "No se identifica la lengua poética con el lenguaje des-

2 Heinrich Lausberg, Manual de retorica literaria, II, Gredos, Madrid, 1967 ; p. 48.

3 Jall Mukarovsky, On Poetic Language, The Peter De Ridder l'ress, Lisse, 1976; p. 7 . 
tinado a expresar sentimientos, es decir, con el lenguaje emotivo" (Mukarovsky). Esta clara distinción entre lenguaje poético y lenguaje emotivo, la comparte Mukarovsky con Jakobson, identificados como están ambos para diferenciar Io estrictamente literario de lo que no lo es. Jakobson había señalado en 1919 la clase de parentesco que vincula a estos dos lenguajes: "En los lenguajes emotivo y poético las representaciones verbales (fónicas y semánticas) atraen sobre sí la mayor atención; el lazo entre el aspecto sonoro y la significación se estrecha." 4 Pero esto no quiere decir que los dos se puedan identificar, como ha sido costumbre, para concederle al "reportaje histérico" una calidad estética que de por sí no se posee. Más adelante el mismo Jakobson afirmaba: "Si en el primero el afecto se impone a la masa verbal, si precisamente el 'vapor de la agitación' hace explotar con su impetuosidad los conductos de la expresión sintáctica, la poesía, que no es otra cosa que un enunciado dirigido hacia. la expresión, está regida por leyes inmanentes". 5

Mukarovsky hace hincapié en lo aleatorio y poco confiable de lo emotivo, a secas, respecto de la poesía, pues mientras lo primero no trasciende lo individual, lo segundo es un fenómeno estético que rebasa los moldes particulares y acaso demasiado concretos para alcanzar la universalidad merecida: "El lenguaje poético tiende en esencia a la manifestación de la emoción, que es principalmente inmediata y la cual, para que sea válida, se limita al estado síquico particular del individuo hablante". "La poesía, sin embargo, supera esta clase de conflictos personales o los trata de otra manera. En todo caso Ios estados afectivos, por nobles y sinceros que sean, no son suficientes, estéticamente, para configurar leyes autónomas que puedan organizar el lenguaje más allá de la anécdota.

2.1. De acuerdo con Mukarovsky se dan casos y épocas en que la poesía usa los medios proporcionados por el lenguaje emotivo; "especialmente cuando la expresión poética

* Roman Jakobson, "La nouvelle poćsie russe" en Qucstions de poétique, Du Seuil, Paris, 1979; p. I4.

" Ibid., p. 14.

- Jan Mukarovsky, op. cit. (Las traducciones son nuestras); p. 8. 
quiere poner énfasis en la individualidad muy singular de su creador", como sucedió en el romanticismo. Entonces, oponerse a la frialdad del neoclasicismo era un modo de transgredir la norma; con lo cual se vuelve a decir que la lengua poética es siempre revolucionaria respecto de lo convencionalmente establecido por la costumbre o el uso. $\mathrm{Mu}$ karovsky insiste en que el lenguaje emotivo es apenas parte de un todo, o si se quiere, uno de los elementos múltiples que conforman el fenómeno poético: "[...] la expresión emotiva es sólo uno de los muchos medios que la poesía canaliza hacia sus fines, desde el rico depósito del lenguaje, pues también hay épocas en que lo programático y revolucionario será que prevalezcan los elementos no emotivos", pues así lo exige la razón misma de ser de la poesía. Machá y Gellner, en la poesía checa; Valéry y Mallarmé, en la francesa; Jorge Guillén, en la poesía española, son ejemplo y confirmación de lo anterior.

3. La lengua poética no se distingue plenamente por su carácter concreto. Este ser concreto de la poesía, en su designación, equivale al empleo de lenguajes de comunicación práctica donde la función referencial es prevalente y donde, por consiguiente, no hay lugar a la ambigüedad y polisemia, propias de la poesía. En otras palabras, donde los referentes extralingüísticos y sus términos son complementarios y correlativos.

Pero resulta que el acto de habla por el cual aplicamos un signo lingüístico a una realidad determinada no es tan sencillo como parece. No se trata de una simple selección tal como la entiende Jakobson, tomando de ejes paradigmáticos las palabras que juzgamos convenientes $y$ adecuadas para un fin. La dificultad del acto mismo de la designación proviene, por parte del poeta, de que "[ . . ] la búsqueda de una expresión lingüística ocurre simultáneamente en dos direcciones; de una parte en la serie de los sinónimos (diferentes designaciones posibles para una sola y la misma cosa), y de otra en la serie de los homónimos (diferentes posibles significados de una sola y la misma palabra). In la designación, por consiguiente, el lenguaje está visualizado desde el 
punto de vista de la realidad designada (sinonimia) y, al mismo tiempo, la realidad designada está contemplada desde el punto de vista de un sistema léxico dado (homonimia) ". 7

3.1. En el acto de la designación se presentan simultáneamente dos actos distintos que de no tenerlos en cuenta dificultan la comprensión de la designación misma. El poeta se mueve dentro de la serie de los sinónimos y busca la manera de seleccionar términos precisos para codificar el mensaje. A su vez, el lector o el oyente, descodifica el mensaje asumiendo de los posibles y diferentes sonidos (homonimia) el significado que juzga necesario y acaso indispensable para una recta intelección del mensaje. Ésta es la razón por la cual Jakobson ha afirmado "[... ] en la codificación, el proceso va del significado al sonido y del nivel léxico-gramatical al fonológico, mientras que el proceso del descodificador desarrolla la dirección contraria, es decir, del sonido al significado y de los rasgos a los símbolos." 8 .

3.2. Este juego constante de sinonimia y homonimia, de palabras múltiples y de significados concretos, es lo que produce el "dualismo asimétrico del signo lingüístico", que Mukarovsky tomó de Karcevsky, y mediante el cual, se establecen constantemente acoplamientos o reacomodos del signans y el signalum, para producir significados que apenas se hallaban latentes en el idioma. "El significante (fónico) y el significado (función) se deslizan continuamente sobre la 'vertiente de la realidad' [...] el significante busca tener otras funciones distintas de su propia función, el significado busca expresarse por medio de otros signos que no son su signo. Son asimétricos; acoplados, existen en un estado de equilibrio inestable. Por este dualismo asimétrico de la estructura de sus signos es que un sistema lingüístico puede evolucionar: la 'adecuada' posición del signo se desplaza con-

Ihid, p. 47.

8 Roman Jakobson, "La lingǘstica y la comunicación", en Ensayós de lingüistica general, Seix Barral, Barcelona, 1975; p. 87. 
tinuamente como resultado de la adaptación a las exigencias de situaciones concretas." 9

3.3. Aunque la lengua poética no esté caracterizada plenamente por una designación concreta, como hemos apuntado, donde referentes extralingüísticos y signos lingüísticos se corresponden mutuamente, el destino de la poesía es más bien el de un vaivén y oscilación continuos entre lo abstracto y lo concreto, entre los significados de las cosas y sus símbolos más o menos coherentes.

Es claro por lo que antecede, que el proceso de la designación puede ser factor de creación de significados nuevos, patrocinando así renovación e innovación de los campos semánticos. Mukarovsky no ha dicho en ninguna parte que la designación concreta no sea en ocasiones también una designación poética, entendida ésta como una desautomatización, en el sentido que le señaló V. Shklovski: "En arte, la liberación del objeto del automatismo perceptivo se logra por diferentes medios [...]. El procedimiento de singularización en Tolstoi consiste en no llamar al objeto por su nombre sino en describirlo como si lo viera por primera vez, y en tratar cada acontecimiento como si ocurriera por primera vez." 10 De hecho la designación tiene dos casos extremos: "No debemos olvidar, sin embargo, que hay una riqueza de matices, muchos de los cuales son frecuentes entre dos casos extremos: la absoluta desautomatización del léxico y la absoluta automatización del acto de la designación." 11

4. No es tampoco la naturaleza "figurada" una caracteristica incondicional del lenguaje poético. Hay dos razones para ello: 1) la designación figurada viva es común al lenguaje en general, ya que la función poética es inherente al sistema de la lengua; 2) a veces, también, la expresión lingüística se aparta de las formas figuradas que se congelan históricamente en su manifestación artística. Además, por la naturaleza cambiante del lenguaje poético, la imagen figurada deja

- S. Karcevsky, Du dualisme asymetrique du signe linguistique, Travaux du Circle Linguistique de Prague, I, Praga 1929; p. 15.

${ }^{0}$ Victor Shklovski, "El arte como artificio" en Teoria de la literatura de los formalistas rusos, Ediciones Signos, Buenos Aires, 1970; p. 61.

${ }^{1 .}$ Jan Mukarovsky, op. cit.; p. 46. 
de serlo cuando se lexicalizan las metáforas, haciéndose trivial, lo que tuvo el sello creador de la innovación.

4.1. Con todo, Mukarovsky ha señalado algunos factores que, de incidir en la designación, son determinantes del lenguaje poético. En primer lugar, lo que el mismo autor denomina la "revitalización" del acto de la designación por procedimientos que en esencia son propios de la retórica poética: "El más alto grado de la desautomatización del acto de la designación tendrá lugar, si una designación figurada es seleccionada de una esfera semántica completamente ajena a la designación común que es la propia; la imagen alcanza entonces el nivel de una designación original. Estos diversos grados de desautomatización de la designación no tienen que ser siempre acoplados a una intencionalidad estética y no tienen que emplearse sólo en poesía; no obstante, cada uno de ellos es más frecuente en poesía que en cualquier parte". ${ }^{12}$ En segundo lugar se vuelve a insistir en que el fenómeno observado del "dualismo asimétrico del signo lingüístico" reacomoda el signans y el signatum, respecto de la realidad nombrada, para producir un significado que no es el convencional: "La designación por la cual el hablante se decide en el acto de la designación, se encuentra en el punto de intersección de las dos series, la de los homónimos y la de los sinónimos. Este punto de intersección no está proporcionado de antemano, como es natural, sino que llega a existir sólo en el acto de la designación, principalmente en una designación original que establece una relación referencial entre palabra y realidad." 13

4.2. Si pudiera parecer que se da una confusión entre la designación figurada y la no figurada, o que la lengua poética oscila caprichosamente entre uno y otro de los dos extremos, sin definirse, lo que sucede es que nadie ha dicho la última palabra sobre la designación poética. No se identifica con la designación figurada; carece de un definitivo carácter concreto; "ni siquiera 'lo excepcional', lo privativo que la alejan de una designación común, abarcarían el rasgo necesario que la distinga..." Las más comunes designaciones

Is Ibid., p. 46.

${ }^{23}$ Ibid., pp. 47-48. 
pueden, también, encontrarse en casi cada texto poético, y ellas son igualmente componentes de la estructura poética. "Si se van a averiguar la técnica y la función estructural de una designación en un texto, se deben tener en cuenta todas las designaciones." Y finalmente:

Hemos afirmado ya que la diferencia entre la designación figurada y la no figurada no está plenamente establecida, sino que hay gradaciones y transiciones entre los dos: una designación figurada no es otra cosa que la homonimia o la sinonimia extremadamente pronunciadas. Añadamos todavia (termina diciendo Mukarovsky) que ni siquiera en poesia una imagen es siempre una designación "nueva" y "no habitual"; compárense las llamadas imágenes-cliché que, con frecuencia, son mucho más "ordinarias" que las designaciones no figuradas. ${ }^{14}$

5. Ni siquiera la "individualidad de la expreșión", Ia particularidad enfática de la expresión lingüística, es característica de la lengua poética en general. Lo que limita la invención individual es la presencia de normas y convenciones que rigen de antemano la elaboración del discurso; las palabras, las imágenes, los patrones lingüísticos que se pueden emplear ya están señalados:

Existen campos enteros de la poesía cuyos cánones estilísticos están y'a hechos de convenciones fijas, claras, de fórmulas obligatorias para cada individuo que crea; a este respecto, véase por ejemplo la épica heroica griega y eslava donde se habla de: "largas lanzas con sombra", "el blanco pecho", "el mar azul" [ $\ldots]$ De este modo, la individualidad en tales creaciones poéticas está obviamente relegada a una posición secundaria y lo que se le permite al autor es apenas alguna libertad para el arreglo de fórmulas dadas con anterioridad, a priori.15

5.1. Hasta aquí Mukarovsky señaló algunos aspectos que tradicionalmente se consideran característicos de la lengua poética, pero sólo de algún periodo determinado o de algún

14 Ibid., p. 9. 
tipo especial de poesía. No existen marcas definitivas del lenguaje poético. Lo único cierto es su cambio; lo imprevisible que, en un momento dado, que siempre es diferente, viene a contravenir la norma y la costumbre habituales. "La lengua poética está caracterizada permanentemente sólo por su función; sin embargo la función no es una propiedad, sino la manera de utilizar las propiedades de un fenómeno determinado", enfatiza Mukarovsky. Que el fenómeno dado sea un sistema de lengua, y que las propiedades sean los subsistemas de la lengua con sus funciones específicas, se colige en seguida de algunas consideraciones que el autor no discute, fundadas como están en los hallazgos de la lingüística estructural de Moscú y Praga, que enumeramos a continuación: a) "La lengua poética es parte de un todo, es decir, una de las diferentes lenguas funcionales, según sean los fines a que el discurso se dirige"; $b$ ) "El efecto estético es la finalidad de la expresión poética"; y c) "La función estética, que es la dominante de la lengua poética y sólo fenómeno concomitante en las otras, funciones (lenguas funcionales), concreta su atención en el signo lingüístico mismo, apartándose así de los lenguajes de comunicación práctica cuya finalidad es el mensaje."16

5.2. El hecho de estar el signo de la lengua poética orientado "hacia sí mismo", o sea, hacia la expresión, tiene algunas consecuencias importantes como son las de no perder de vista las otras funciones extraestéticas de la lengua, conocidas según la terminología de K. Bühler. "La expresión lingüística en su orientación estética oscila entre ellas, libremente; en cualquier momento puede acompañarlas o apartarse de ellas, las puede combinar a su gusto." 17

Además, extrae los materiales léxicos con que trabaja donde los encuentra, aunque no pertenezcan a su dominio, cosa que no acontece con las otras lenguas funcionales del sistema, las cuales son más o menos autosuficientes. "Esto es lo que distingue al lenguaje poético de los demás niveles lingüísticos pues, por regla general, éstos hacen uso de sus propios medios, con excepción, naturalmente, de lo que es

1s Ibid, p. 9.

${ }^{27}$ Ibid., p. 10. 
común propiedad lingüística; y este hecho anotado es lo que vincula a la lengua poética con los otros niveles convirtiéndola en mediadora de sus interrelaciones y de su interpenetración."18

6. Entre los lenguajes funcionales hay uno con el cual tiene especiales contactos y relaciones. Se trata de la lengua literaria, tal como la definen las Tesis de Praga. ${ }^{10}$ No es fácil delimitar estas relaciones entre ambos lenguajes, pues en esencia se refieren a los mismos problemas de la-designación, figurada y no figurada. Pero dos cosas son claras: 1) "La lengua literaria es el trasfondo contra el cual se percibe el aspecto lingüístico de la obra de arte", pues, en efecto, existe siempre un marco referencial necesario que ya no se pierde de vista cuando se hace uso de los lenguaje no rectos; y 2) "Toda desviación del uso literario común es lo que en. poesía adquiere el valor de un procedimiento artístico",20 lo cual no sucede en las otras funciones de la lengua que no sea la poética.

6.I. Con todo, hay una serie de influencias y rechazos que ponen de manifiesto las relaciones dialécticas de ambos lenguajes. Por una parte la poesia ejerce su influjo en el desarrollo de la norma literaria. "Esta influencia no es tal, sin embargo, que todo lo creado por la poesía con respecto al lenguaje, inmediata y automáticamente, llegue a ser parte de la norma literaria. Son precisamente las más sorprendentes creaciones lingüísticas de la poesia, es decir, los neologismos, los que más raramente se originan en la lengua literaria." 21

Y lo más extraordinario es todavía que el neologismo poético no reclama ser aceptado unívocamente y por todos, como es el caso de los neologismos de la ciencia, porque aquél no tiene un uso práctico. Por otra parte también la lengua poética crea constantemente estructuras más efectivas para la comunicación, jerarquías sintácticas más amplias .

28 Jid., p. 12.

19 B. Trnka et al., El Circulo de Praga, Ed. Anagrama, Barcelona, 1971; p. 45 .

i Jan Mukarovsky, op. cit; p. 12.
I Ibid., p. 13 . 
que la lengua literaria no acepta de plano, dado su carácter conservador, pero que, en realidad, se ve urgida a recibir ante "la necesidad de expresarse sobre materias que no tienen relación directa con la vida real, y sobre materias nuevas [...] que la lengua popular no posee o no poseía hasta entonces". ${ }^{22}$ Por fin, to que es revolucionario desde el punto de vista de la lengua nacional no lo es desde el punto de vista de la poesía y viceversa. A pesar de su influjo mutuo, ambos lenguajes mantienen su soberanía.

6.2. Lo que sigue es quizá una de las afirmaciones más esclarecedoras sobre el tema que nos ocupa. Después de las caracterizaciones del lenguaje poético antes enunciadas, ninguna de las cuales es permanente, aparece una que sí lo es. "La lengua poética, después de todo, como toda lengua funcional tiene su raíz en una lengua nacional particular. Este hecho, con toda su aparente obviedad, adquiere importantes consecuencias que hace poco se hicieron claras a los teóricos de la poesía e historiadores de la literatura". ${ }^{23}$ Luego, ofrece las razones de este hecho que más tarde explicará con abundancia cuando hable de la esencia del cambio lingüístico, cuyo punto culminante se encuentra en el desarrollo del lenguaje poético. Los componentes de una lengua funcional son muchos; cada uno de ellos se organizan de acuerdo con los fines que persigue el hablante y de acuerdo también con las condiciones sociales de cada momento y cada época. Todo acontece, sin embargo, dentro del marco exigente $y$ exacto de una lengua nacional definida. Lo que está permitido en un determinado sistema lingüístico, no opera eficazmente en otro distinto: "Cierto procedimiento poético adquiere características que son enteramente diversas de aqueIlas obtenidas en otras lenguas, cuando son de naturaleza distinta." Y cita el caso estudiado por Jakobson en Fundamentos del verso chęco, donde los mismos versos de Pushkin traducidos literalmente al checo por A. V. Jung dieron una versión profundamente diversa de lo que el verso ruso contenía originalmente.

6.3. Cada literatura nacional tiene sus propias exigencias

22 B. Trnka et al., op. cit.; p. 44.

23 Jan Mukarorsky, op. cil.; p. 15. 
lingüisticas porque no pertenece a los esquemas de otras lenguas. Aplicar los requerimientos propios de un movimiento literario, de una nación, a otros movimientos similares en otras lenguas y naciones es exponerse a resultados que contradicen la significación del movimiento mismo en su país de origen. Una cosa son las ideas teóricas y otra, la aplicación de las mismas, regidas por otros sistemas lingüísticos. "El simbolismo checo es, en esencia, un fenómeno diferente y tiene una significación diferente en la evolución literaria local, de lo que tuvo, por ejemplo, el simbolismo francés, en Francia, el ruso, en Rusia, aunque las ideas teóricas de los simbolistas mismos hayan sido semejantes en toda Europa". ${ }^{24}$ Razón por la cual Mukarovsky afirmó con certeza:

En realidad, hay toda una multitud de lenguajes poéticos no sólo entre las naciones, sino también dentro de una litera. tura nacional dada. Cada género poético representa una estructura lingüística que se basta a sí misma hasta cierto punto; algunas veces la diferenciación lingüistica está igualmente subrayada por el uso de diferentes dialectos, como acontece en la antigua poesía griega. ${ }^{25}$

7. Mukarovsky ha considerado al lenguaje como una especie de material laborable con el cual cada creador se encuentra a solas para hacer de él un instrumento adecuado o no, según sea la capacidad del orfebre. Desde este punto de vista que no es el del sistema lingüístico, sino el de la obra de arte en proceso de elaboración, el lenguaje "es un material como el metal y la piedra para la escultura, como el pigmento y los materiales del plano pictórico para la pintura, etcétera. El lenguaje también adviene a la obra desde fuera, como fenómeno sensorialmente perceptible, para llegar a ser el vehículo de la estructura no material de la obra. .,"26

Ante esa perspectiva de trabajo práctico no habría que ol-

* Ibid., p. 15.

* Tlid., p. 19.

so Ibid., p. 13 . 
vidar que el creador saca sus materiales no sólo de las esferas léxicas propias del tema, sino también de las canteras del idioma que para ser dominado tiene que ser conocido a fondo y estudiado con esmero. Máxime cuando ese material tiene muchas posibilidades latentes cuya realización depende del tratamiento artesanal que reciben, porque para el orden de la palabra poética entran en juego tres puntos de vista: el ordo, la junctura y el numerus, como afirmó Quintiliano. Los tres afectan a la sintaxis y a la semántica, a la eufonía y al ritmo, tan determinante este último en poesía. La junctura tiene que ver mucho en la estructuración rítmica porque no es otra cosa que la aproximación inmediata de los miembros de un texto dado. Lausberg ha observado que "las prescripciones de la junctura se ejemplifican principalmente en la sucesión de las palabras individuales en la oración". ${ }^{27}$ Con lo cual queda dicho que la palabra es un material de trabajo sometido a procedimientos artesanales técnicos.

7.1. Mukarovsky diferencia, sin embargo, al lenguaje, como material, de los otros materiales artísticos: "Piedra, metal, pigmento, etcétera, ingresan al arte como simples fenómenos naturales que adquieren una naturaleza semiótica sólo en él; comienzan a 'significar' algo sólo en el arte." El lenguaje, por el contrario, ya significa "algo", mucho antes de entrar en contextos semánticos nuevos. "Existe y opera fuera de la poesía como el más importante sistema de signos, como un signo $\chi \alpha \tau^{\prime} \varepsilon_{\xi} \gamma_{\eta} \eta \dot{v} v$, i.e. èn calidad prominente; contiene el aglutinamiento de la vida humana y reglamenta, por igual, la actitud del hombre hacia la realidad y la sociedad." 28

7.2. A título de información transcribo la página en que Mukarovsky aproxima lenguaje y tono musical, insertados ambos en sistemas mayores:

Sólo el tono, material de la música, que también no es mero sonido natural sino el componente de un sistema tonal (lo entendemos únicamente como parte de un sistema tonal) se

27 Ibid., p. 356.

${ }^{25}$ Ibid., p. 14. 
aproxima al lenguaje como material artístico en su carácter semiótico. El tono musical es también, hasta cierto punto, independiente de su realización sonora; expertos músicos pueden leer una partitura en silencio, tanto como un lector puede leer un libro. En contraste con el lenguaje, sin embargo, el tono está limitado en su existencia casi completamente a la música; la naturaleza, con raras excepciones, no tiene tonos (el tono de la arena que se desliza en las clunas se cita como caso único de tono natural). Fuera de la música los tonos aparecen únicamente en la periféria de la actividad humana y en estrecha conexión con ellas; tales son, por ejemplo, las señales dadas por claxons. Por consiguiente el tono no pertenece en la práctica de la vida, y no es vehículo de un significado determinado. ${ }^{29}$

8. Si, como hemos dicho, no existe ninguna propiedad sola y aislada que de manera exclusiva caracterice a la lengua poética, hay algo, sin embargo, que le es congénito: su "impresión de desviación" como dice Mukarovsky, contra todo lo congelado, prescrifo o sancionado y defendido por las normas vigentes. En otras palabras, lo que sí es sintomático y permanente de ella es su cambio, su versatilidad, capaces de hacer que el péndulo de la poesía pase intempestivamente de un extremo a otro, sin que pierda su continuidad el fenómeno poético. De ese modo, aunque en ocasiones frecuentes, la poesía parezca definirse por la lengua común y sencilla $y$, en otras, por la lengua elaborada de la retórica, no obstante ninguna de las dos posiciones es la definitiva, ni cumple a cabalidad con una intencionalidad estética, única y absoluta: "Ninguno de estos estados, ni la más grande separación recíproca entre lengua poética y lengua literaria, ni su máxima aproximación ni, finalmente, el término medio ('el medio dorado'), son su ideal permanente, pues el lenguaje poético es cambio constante." Lo esencial, será siempre la búsqueda de otro nivel semántico, la forma desautomatizada, ávida de poner en movimiento lo que la costumbre trata de inmovilizar.

8.1. Si la mutabilidad es la esencia de la lengua poética 
existen razones muy válidas para explicar el cambio; razones que no son únicamente las de la moda o las del capricho personal en la cambiante voluntad de los poetas. En primer lugar el desgaste que tienen las palabras en el comercio cotidiano de la comunicación: "La eficacia estética de cualquier procedimiento se esfuma después de cierto tiempo a causa de la desautomatización; es decir, por la vulgarización y generalización."30 En segundo lugar la naturaleza social del lenguaje que modifica a cada paso no sólo "el uso que la poesía hace de los instrumentos lingüísticos proporcionados por la lengua literaria", sino también las fuentes de donde éstos proceden. Pero sobre todo, el lenguaje poético cambia porque no es monolítico en su constitución, sino la suma de elementos cuya ubicación se altera de acuerdo con la importancia que cada uno de ellos adopta dentro de un texto dado. De ese modo los componentes se reordenan y buscan el lugar que les corresponde según sean las exigencias del efecto estético deseado. "Cada vez que un componente llega a ser el primero cambia el orden de todos los otros componentes, porque todos los componentes de una obra poética están interconectados por relaciones múltiples que penetran la estructura de la obra. Tan pronto como un componente asume la primacía arrastra consigo a aquellos que están más próximos a él y empuja a los otros hacia el fondo." 31

Que el cambio sea lento o rápido no importa; siempre estará en función de revitalizar el lenguaje, de redenominar. los posibles aspectos desconocidos de la realidad. Lo evidente es que la historia de las culturas no se detiene, ya que, en última instancia, los estilos artísticos y los movimientos literarios no son más que evisiones inéditas del mundo. La función poética del lenguaje que los expresa temporalmente, es la causa eficiente de ellos.

Luis Enrique Senvoya

Seminario de Poética.

Instituto de Investigaciones Filológicas.

so Ibid., op. cit.; p. 17.

at Ibid., op. cit.; p. 18. 